\title{
OS USOS DO ABUSO SEXUAL
}

\author{
LOS USOS DEL ABUSO SEXUAL \\ THE USES OF SEXUAL ABUSE
}

\section{Gisele Scobernatti ${ }^{1}$ e Henrique Caetano Nardi ${ }^{1}$}

${ }^{1}$ Universidade Federal do Rio Grande do Sul, Porto Alegre/RS, Brasil

\begin{abstract}
RESUMO: Este artigo analisa as narrativas de mulheres e homens; mães e pais; cuidadoras e cuidadores de crianças e adolescentes envolvidos em denúncias de abuso sexual, na condição de vítimas, e que foram, por essa razão, inseridas/ os no sistema de garantia de direitos, objetivando demonstrar o que pensam, que enunciados utilizam para falar sobre o abuso sexual e os sentidos atribuídos à sua inserção na rede de atendimentos. Para auxiliar a operar teoricamente utilizou-se a noção de biopolítica, enquanto uma forma de governo e uma tecnologia do poder de Foucault, associada às ideias de um governo pela psicologia de Castel e à retórica do trauma de Fassin. A partir da análise, é possível descrever como o abuso se torna a forma de legitimação maior para que se possa acessar a proteção do Estado e como as formas de governar capturam a todos/as e balizam as narrativas em sutis esferas.
\end{abstract}

PALAVRAS-CHAVE: Abuso sexual; Sistema de garantia de direitos; Infância; Psicologização.

RESUMEN: Este artículo analiza las narrativas de mujeres y hombres, madres y padres, cuidadores de niñas, niños y adolescentes involucrados en denuncias de abuso sexual, como víctimas, y que fueron, por eso, insertados en el sistema de garantía de derechos, con el objetivo de demostrar lo que piensan, qué declaraciones utilizan para hablar sobre el abuso sexual y los significados atribuidos a su inserción en la red de asistencia. Para ayudar a operar teóricamente, se utilizó la noción de biopolítica, como una forma de gobierno y una tecnología de poder de Foucault, asociada a las ideas de un gobierno de la psicología de Castel y la retórica del trauma de Fassin. A partir del análisis es posible describir cómo el abuso se convierte en la forma de mayor legitimación para que se pueda acceder a la protección del Estado y cómo las formas de gobernar capturan a todas y todos y marcan las narrativas en esferas sutiles.

PALABRAS CLAVE: Abuso sexual; Sistema de garantía de derechos; Infancia; Psicologización.

ABSTRACT: This article analyzes the narratives of men and women; mothers and fathers and caretakers of children and adolescents involved in sexual abuse allegations, as victims, and that, for that reason, they have been inserted in the Rights Guarantee System, aiming to demonstrate what they think, what statements they use to talk about sexual abuse and the meanings attributed to their insertion in the care network. To facilitate the theoretical comprehension, the notion of Biopolitics was used as a type of government and one of Foucault's technologies of power, also linked to the ideas of a government for Castel's psychology and to Fassin's rhetoric of trauma. From the analysis it is possible to describe how the abuse becomes the major way of legitimizing in order to access the government protection, and how the forms of government capture all people and support the narratives in subtle ways.

KEYWORDS: Sexual abuse; Rights Guarantee System; Childhood; Psychologization. 


\section{Introdução}

O uso do abuso sexual como forma de mediar conflitualidades familiares já tem sido bastante analisado, sobretudo quando se tratam de falsas alegações que pretendem promover rupturas entre genitores/as e seus/as filhos/as ${ }^{1}$. No entanto, este artigo, por meio da análise das narrativas de mulheres e homens, mães e pais, cuidadoras e cuidadores (aqui denominadas/os usuárias/os) de crianças e adolescentes ${ }^{2}$ envolvidos em denúncias de abuso sexual, na condição de vítimas, e que foram, por essa razão, inseridas/os no sistema de garantia de direitos, procura demonstrar que enunciados são utilizados para falar de abuso sexual e os sentidos atribuídos à inserção na rede de atendimentos. Assim, partindo dos ditos que se cristalizam, buscou-se descrever práticas discursivas e não discursivas em jogo, de tal forma a analisar a rede que constitui a multiplicidade e a complexidade dos fatos e das coisas. E, desse modo, evidenciar não somente aquilo que os/as narradores/ as definem como abuso sexual, mas tudo o que ele significa enquanto violação capaz de produzir discursos e práticas de proteção múltiplas que fazem emergir a condição de vítima enquanto legitimadora dos mecanismos de proteção.

O que a análise aponta é que são narrativas cuidadosamente construídas no sentido de legitimar a demanda e o sofrimento imposto pela violação denunciada, permitindonos vislumbrar a forma como esses/as narradores/as interpretam as relações sociais nas quais estão imersos e o modo como os enunciados referentes à proteção atravessaram e construíram as suas falas.

Essas narrativas também elucidam os percursos, os trajetos percorridos pelas famílias de crianças e adolescentes quando denunciada uma situação de abuso sexual infantil. O conjunto de narrativas aqui analisadas foram fruto de uma pesquisa que buscou compreender a configuração das relações de poder que constituem esse campo da proteção e promoção de direitos de crianças e adolescentes entre outubro e dezembro de 2016, quando essas pessoas eram acolhidas em um serviço ${ }^{3}$ de atenção a crianças e adolescentes vítimas de maus-tratos, negligência e abuso sexual, no município de Pelotas/RS.

As narrativas que foram construindo cada história retratam as trajetórias dos/as usuários/as desde a inserção no sistema de garantia de direitos. Alguns trechos estão aqui registrados entre aspas e em itálico, "outros não estão ditos, mas atravessam as palavras e as construções presentes” (Barros, 2013, p. 31 ).

Foram analisadas as trajetórias de 16 famílias, de 17 crianças e adolescentes, supostamente vítimas de abuso sexual, denunciadas em sua maioria ao Conselho Tutelar, seguido de notificações feitas à Delegacia de Proteção à Criança e Adolescente (DPCA). A análise buscou trazer à cena o que tem sido pensado, compreendido e definido como abuso sexual, "a partir das práticas, a partir dos discursos, a partir de acontecimentos, da descrição de momentos em que certas coisas são objetificadas” (Fischer, 2003, p. 381) como abuso sexual.

As narrativas revelam uma pluralidade de enunciados que buscam explicar/definir abuso sexual. Em algumas, a definição se apresenta numa descrição detalhada de fatos, replicando as possíveis narrativas das crianças e adolescentes vítimas: "ele pega e fala que ela (mãe) bota a perereca no pinto dele, que mexe a cama, que o pinto dele fica forte"; noutras revelam-se apenas como um tipo penal "ela foi estuprada”; ora há, nas narrativas, a enunciação de um quadro de sintomas ditos compatíveis com abuso (ela tem pesadelos todas as noites); 
(voltava pra casa e fazia xixi na roupa); (ele voltava agressivo); há, ainda, aquelas em que o abuso se converte em algo indeterminado, como (atitude suspeita), (comportamento sexualizado) ou ( $f e$ z o que tinha que fazer).

Plurais são também os desdobramentos das histórias de abuso sexual denunciadas e aqui narradas: somente sete delas evidenciaram indicativos de vitimização sexual, contudo em somente duas não se identificaram outras vulnerabilidades associadas; nas cinco outras situações em que se identificaram sinais de vitimização, havia tantas fragilidades, sobretudo de natureza social, que o abuso sexual parece desaparecer em meio a vidas tão precárias. Mas alguns dados merecem atenção, a maioria dos/as cuidadores/as que participaram deste estudo eram mulheres e, em sua totalidade, viviam numa condição socioeconômica bastante desfavorável ${ }^{4}$.

Nas demais histórias não se encontraram indicativos que confirmassem a denúncia, mas se perceberam diversos usos que o abuso vai ganhando quando se fala de proteção e promoção de direitos de crianças e adolescentes. Acionam-se enunciados para justificar a denúncia e legitimar a consequente inserção no sistema de garantia de direitos, enunciados que falam de um lugar da vítima e seu sofrimento associado à violência e à urgência de medidas reparadoras, neste caso, a justiça e o tratamento.

Interessa-nos, contudo, interrogar por que cedemos todos/as mesmo diante de evidências frágeis? Por que nos deixamos convencer por indeterminações e imprecisões que pretendem sugerir abuso sexual? Por que, mesmo não crendo no abuso, nos deixamos levar por argumentos que censuram o diverso nos modos de ser e de viver? Ou, ainda, por que a menção do abuso nos impede de escutar outras demandas presentes nas narrativas e que não recebem a atenção do Estado? ${ }^{5}$

Sejam quais forem os matizes impressos em cada história, sejam quais forem os desdobramentos de cada uma delas, sejam quais forem os argumentos que justifiquem a inserção dessas histórias no sistema de proteção e promoção de direitos, podemos pensar junto com Foucault quando ele diz que desde o século XVIII o sexo das crianças passou a ser o foco de "inúmeros dispositivos institucionais e estratégias discursivas" (Foucault, 2007, p. 36).

\section{A proliferação dos discursos acerca do abuso sexual}

Quando a metade do século XIX se abriu à jurisdição miúda dos pequenos atentados, dos ultrajes de pequena monta, uma série de controles sociais se puseram em funcionamento no sentido de filtrar a sexualidade dos casais, dos pais e dos filhos protegendo, separando e prevenindo os perigos que estão em toda a parte (Foucault, 2007).

Da incitação aos discursos sobre sexo que caracterizaram a virada dos séculos XVIII para XIX; dos deslocamentos dos discursos acerca do pecado-salvação do domínio religioso para o corpo e a vida feitos mediante uma codificação clínica, vemos nascer o fazer falar (Foucault, 2007). Instaura-se um dispositivo capaz de produzir discursos sobre o sexo conjugando a velha confissão aos métodos da escuta clínica, a sexualidade tornou-se o "correlato de uma prática discursiva que é a scientia sexualis (Foucault, 2007, p. 78), que toma para si o estudo das perversões e passou a definir indivíduos imiscuindose nas mais finas ramificações do ser. Constituiu-se, então, um saber rigoroso sobre o sexo e o indivíduo, um saber pormenorizado, capaz de normalizar algumas condutas e desqualificar outras. 
Inserimos o abuso sexual nessa intersecção entre a técnica de confissão e uma discursividade científica sobre sexo e tudo o que lhe escapa e tudo o que transgride a norma. Falemos, então, de uma sexualidade que se abre ao dito patológico e que, por essa razão, requer intervenções terapêuticas ou de normalização (Foucault, 2007, p. 78) e, assim, vimos ampliar-se o leque das práticas a serem descritas como sendo abuso sexual; práticas institucionais que vão encontrar força nas construções discursivas correspondentes e, assim, disseminam-se discursividades que passam a vigorar como regimes de verdade.

Assim, mesmo diante das fragilidades presentes em denúncias que remetem a outros problemas que não o abuso; mesmo diante de evidências múltiplas que possam dizer respeito a qualquer coisa e mesmo que a problemática central das famílias fale de vulnerabilidades múltiplas e diversas ao abuso, a sexualidade e o abuso sexual passam a ser a causa de todos os problemas, convertendo-se na violação mais legítima para justificar o acionamento do sistema de garantia de direitos. Reafirmando o que disse Foucault, "nas relações de poder, a sexualidade não é o elemento mais rígido, mas um dos dotados de maior instrumentalidade: utilizado no maior número de manobras, e podendo servir de ponto de apoio, de articulação às mais variadas estratégias” (2007, p. 114).

Tal assertiva aplica-se, também, ao abuso sexual que, por seu conteúdo sexual, ou por falar do sexo das crianças, também faz com que os discursos proliferem, intensifiquemse, e cria-se a ideia de perigo incessante, de modo que comportamentos infantis ditos sexualizados ou sexualidades "avançadas", como aqueles identificados nos relatos, como, por exemplo: uma professora no caso dos dois irmãos que brincavam com seus corpos na escola de Educação Infantil, a recusa de uma menina de três anos de que a avó e a tia toquem sua genitália durante o banho, ou o machucado no ânus de um garoto de quatro anos, ganham status de sintoma inequívoco de abuso sexual e nos conduzem a denunciar para diagnosticar, acumular relatórios e organizar terapêuticas em torno do abuso sexual, e sempre por meio da incitação de falar sobre, como se fôssemos tomados por uma "uma espécie de erotismo discursivo generalizado" (Foucault, 2007, p. 39) sobre sexo e tudo que a ele diz respeito. Agora o fazemos em nome da proteção.

Por esse caminho, o abuso sexual tem ganhado atenção, a centralidade e o interesse não apenas das ciências médicas, humanas, sociais e jurídicas, como também da imprensa, fazendo proliferar os discursos em torno de si, produzindo inúmeros mecanismos de apoio e proteção àquelas que possam ser vitimadas por tal forma de violência, bem como de responsabilização de seus autores.

Em toda parte alguém se diz especialista no assunto, as reportagens, as notícias veiculadas na imprensa alertam para alguns sinais de que a criança possa estar sendo molestada sexualmente, criam-se campanhas para prevenir o abuso e dentre as premissas de tais campanhas está um comportamento hipervigilante dos pais, dos educadores, dos familiares, dos enfermeiros, dos agentes comunitários de saúde, dos visitadores do PIM (Programa Infância Melhor), enfim, de todos aqueles pertencentes a lugares por onde circulam crianças. Todos mobilizados no enfrentamento e no combate ao abuso sexual. Todos vigilantes.

Em relação ao sexo, ou em relação a tudo que lhe envolve, tornou-se algo que é preciso examinar, vigiar, confessar e transformar em discurso e, "assim um conjunto de coisas ditas e não ditas, uma série de instituições, de práticas, de decisões regulamentares, de leis, medidas administrativas, enunciados científicos, proposições filosóficas, morais, filantrópicas" (Foucault, 1998, p. 244), que darão à sexualidade uma centralidade a 
partir da modernidade, convertendo-a, segundo Foucault (2007), num dispositivo capaz de assegurar a gestão individual do corpo e das populações, bem como a normalização das condutas.

O dispositivo é de natureza estratégica, deixa escapar as relações de poder que vão constituindo e sustentando saberes, temos como efeito o sexo funcionando como dispositivo disciplinar, classificando o comportamento dos sujeitos como normal ou desviante. Desse modo, o sexo deve ser visto como estratégia do poder para dirigir a conduta dos indivíduos e mapear os seus comportamentos.

Assim, quando cedemos e/ou acolhemos denúncias, demandas por suspeição daquilo que antes de ser uma possível transgressão sugira estranhamentos diante de modos diversos de viver, estamos movidos por esse dispositivo da sexualidade que tem servido há algum tempo como modo de regulação da população. Tornamo-nos parte de um Estado que precisa saber

o que se passa com o sexo dos cidadãos e o uso que dele fazem e, também, que cada um seja capaz de controlar sua prática. Entre o Estado e o indivíduo o sexo tornou-se objeto de disputa, e disputa pública; toda uma teia de discursos, de saberes, de análise e injunções o investiram. (Foucault, 2007, p. 33)

Diante da crescente proliferação de discursos sobre abuso sexual que lhe conferiram grande instrumentalidade, somos convidados a aprender a conviver com a polissemia de repertórios que circulam nos espaços que habitamos cotidianamente e com a complexidade dos jogos de posicionamento: reconhecer a partir de que posições nossos interlocutores falam e em que posições somos colocados (Spink, 2013).

\section{O impensado desejo infantil}

O veto à manifestação franca da sexualidade ou ao desejo imposto pela avó fez Júlia ${ }^{6}$ buscar nas alegações de abuso sexual um caminho para, dez anos depois da ruptura provocada pela revelação da homossexualidade de sua mãe, evidenciar o conflito familiar central incomodamente construído em torno do eixo sexualidade-desejo-prazer.

Foi Leocádia, a avó materna de Júlia, quem participou do acolhimento no NACA, é ela quem toma conta da neta desde que sua filha foi embora. Ambas chegaram ao NACA encaminhadas pela Delegacia de Proteção à Criança e ao Adolescente - DPCA, em razão da denúncia de estupro contra Júlia, que na época estava com 13 anos.

Segundo Leocádia, Júlia saiu para fazer uma prova à tarde, como várias vezes aconteceu, mas nesse dia atrasou muito e a avó ficou bastante preocupada, pois costumava ter um controle rígido sobre os horários de Júlia. Ela não só não voltou no horário habitual como, quando chegou em casa bem mais tarde, disse ter sido estuprada por algum desconhecido que a havia atacado na rua. Imediatamente a avó a levou para a Delegacia, onde registrou BO (Boletim de Ocorrência). Júlia foi encaminhada para exame de corpo de delito no IGP (Instituto Geral de Perícias), para o NACA para a realização de Avaliação Interdisciplinar e ao CAPS I em razão de ideação suicida. 
Depois de observarem algumas contradições entre os relatos de Júlia e as provas levantadas, os investigadores tornaram a ouvir a garota que, ao ser questionada sobre algumas incongruências, contou que a história não era aquela e sim que havia conhecido um garoto de 16 anos e que, em lugar de ir fazer a tal prova, foi encontrar-se com ele na casa dele, que morava com seu avô, e lá ele a teria obrigado a fazer sexo.

As revelações de abuso sexual sempre implicam crises. No caso de Júlia ela não simplesmente mentiu sobre os abusos, ela precisava revelar uma conflitualidade familiar centrada na sexualidade ou, melhor dito, nas dificuldades em relação à sexualidade. Nascido na crença de que as crianças sejam seres inocentes, puros e desprovidos de uma sexualidade, de desejos e de prazeres, o impensado desejo infantil, quando eclode no seio de famílias conservadoras, como a de Júlia, vai evidenciar todas as dificuldades em lidar com a constatação de que a sexualidade existe e tem lá seus apelos.

E Leocádia, a avó, parece não conseguir avaliar e compreender o tamanho do sofrimento da neta expresso em mais de uma tentativa de suicídio; também não busca entender as razões pelas quais a neta precisou criar duas versões de violência sexual para poder voltar para casa. E assim, ela repete, recusa a enfrentar a situação com desassombro, nega-se a aceitar qualquer manifestação dissidente (quanto aos seus valores morais). Sua fé, sua religiosidade ativa e praticante parece não conseguir dar alívio a suas angústias, seja quando descobriu que a mãe de Júlia era homossexual, seja agora, quando Júlia busca nas falsas denúncias de abuso sexual um modo de revelar que transou com um garoto.

A recusa de Leocádia em admitir a possibilidade de um desejo e reconhecer a sexualidade da neta como algo natural está expresso em narrativas como

ela tem 13 anos, o delegado perguntou sobre ereção e ela não sabia o que era, ela é uma menina grande, bonita, vistosa, mas ela é muito infantil, ela não sabia o que era ereção, imagina, e eu não me sentia à vontade de conversar sobre sexo e essas coisas com ela porque ela é muito meiga, ela é muito sem maldade. Então eu falava as coisas pra ela muito por cima, não era clara, porque achava que não era a hora ainda, então aquilo aconteceu sem ela estar preparada.

E aqui Leocádia sugere que Júlia seja uma criança alheia e indiferente à sexualidade, pouco mais que um bebê, mas Júlia é, na verdade, uma adolescente, e se ela precisou lançar mão de duas versões de abuso sexual para poder justificar a mentira e o atraso na volta para casa não é difícil acreditar que ela não revelaria os seus conhecimentos sobre sexo para a avó, ao escrivão ou ao Delegado. Do mesmo modo que o desconhecimento também pode sugerir a falta de informações adequadas e, nesse sentido, a avó já revelou suas razões para omitir-se; quanto à escola, de orientação religiosa alinhada com a avó, possivelmente também não tenha abordado o tema de forma isenta.

Leocádia e seus pudores não apenas evidenciam uma vida pautada num regramento cisheteronormativo, mas também sua condição refratária a toda e qualquer interferência externa que contrarie as suas verdades. Sua generosidade de uma pessoa "temente a Deus" logo se desfaz quando Júlia, depois de mais uma tentativa de suicídio, vai morar com a mãe e ela manifestamente deseja que tudo dê errado para elas, num desejo de vingança. Do mesmo modo que a sua aceitação quanto ao atendimento psi vai até o limite de ser contrariada pelas profissionais, deixando de comparecer porque lhe foi assinalado o sofrimento evidenciado por Júlia. Assim, Leocádia e seus rigores vão impedindo, dificultando o fluir 
das sexualidades, não somente daquelas, a exemplo da mãe de Júlia, dissidente do modelo heteronormativo, mas também daquelas que habitam lugares impensados por ela, como é o caso das crianças, das/os adolescentes, como é o caso de Júlia.

O uso das alegações de abuso sexual por Júlia se revelou um modo complexo de revelar conflitualidades familiares que gravitam em torno da sexualidade. A denúncia, num primeiro momento, funciona como um evitador de conflito - ela consegue voltar e ser aceita em casa por causa do abuso - o abuso sexual converte-se na sequência como um mediador dos conflitos; a falsa notificação permitiu a Júlia que as demandas de natureza afetivossexual transbordassem do impermeável território familiar para outras esferas onde pudessem ser acolhidas e ouvidas.

\section{O lugar da vítima e outros interlocutores}

A problemática da violência no Brasil privilegiou por um longo tempo a sua relação com a criminalidade e a justiça. A partir do ECA e da implementação da Doutrina da Proteção Integral, testemunhamos um alargamento do espaço social ocupado pela vítima e a construção da pessoa como vítima no mundo contemporâneo é pensada como uma forma de conferir reconhecimento social ao sofrimento, circunscrevendo-o e dando-lhe inteligibilidade (Sarti, 2011 , p. 54). De modo que, toda vez que, em qualquer instância que seja, identificamos sinais ou mesmo diagnosticamos abuso sexual, remetemo-nos à responsabilização social pelo sofrimento imposto; legitimando demandas e ações de reparação e cuidado. Em nome da reparação do dano, em nome do cuidado, opera-se pela lógica do trauma e, nesse sentido, ganham cada vez mais legitimidade profissionais do campo da saúde mental, mais precisamente os vinculados aos saberes psi (Fassin \& Rechtman, 2007; Sarti, 2011); a esses profissionais têm se atribuído tanto o cuidado pelo sofrimento das vítimas quanto o encargo de fornecer provas acerca da violência sofrida.

Assim, a retórica do trauma se impõe para que as crianças pretensamente sexualmente abusadas existam nessa condição de vítimas e, desse modo, possam ser reivindicados os mecanismos que operam em nome da proteção de crianças. Tal lógica, contudo, parece que subtrai da perspectiva reparadora os aspectos de justiça, esvaziam-se os sentidos históricos e contextuais da figura da vítima e, a vítima, descolada de seu contexto, de suas raízes, reduz-se exclusivamente a sua condição de vítima de abuso sexual ${ }^{7} /$ violência. Nada mais importa ou faz sentido, de modo que a reparação implica apenas a possibilidade de elaborar as experiências de dor e sofrimento, invariavelmente associadas à violência.

Desse modo, quando existe alguma suspeita de que uma criança tenha sofrido abuso sexual, independentemente da sua história de vida, do contexto social e político em que está inserida, independentemente da multiplicidade de formas e modos de expressão do viver, a intervenção é sempre a mesma, as técnicas, os equipamentos e os enunciados acionados são sempre os mesmos, essa lógica de reparação do sofrimento imposto pela violência não somente individualiza a experiência, cabendo à figura da vítima a expressão obrigatória dos sentimentos, como torna imperativa a presença de uma escuta especializada para acolher tal demanda. 
Fassin e Rechtman (2007) advogam que vivemos tempos onde se retira dos direitos sociais um lugar de centralidade e os realoca sob a perspectiva de exceção e é a exceção que propomos pensar aqui as situações denunciadas como abuso sexual, retomando-se a análise das histórias narradas. Excetuando-se duas histórias em que o abuso sexual figurou como uma forma de violência infantil, sem que se identificassem outras fragilidades, todas as demais histórias falavam de desamparo, de abandono e das precariedades no viver; as histórias visibilizadas em nome do abuso denunciam vidas precárias, carentes de suportes sociais, vidas tão cheias de exigências outras que o abuso torna-se o menor dos problemas, mas a desigualdade social presentes nessas histórias é substituída pela noção de criança vítima e sofredora e esse sofrimento precisa ser avaliado e acompanhado por saberes vigilantes e garantidores da segurança (Brito, 1993), de tal forma que os vestígios da violência passam a ser legitimados por uma perspectiva psicológica e legal.

Legal e psicológica porque a vitimização sexual aciona os mecanismos da proteção que se situam nesse interstício entre os saberes e os poderes, entre o psi e o judicial, entre a lei e a norma. Nesse sentido, proteger crianças vítimas de abuso sexual é atuar no governo da vida; é, nas palavras de Maria Lívia Nascimento, "atuar pela biopolítica, controlando as famílias pelos dispositivos de disciplinarização, mas também regulando-as pelos mecanismos de segurança” (2015, p. 284), da prevenção de riscos e a reparação do sofrimento pelos saberes psi.

Scheinvar advoga que "o conceito central à garantia de direitos, talvez seja a proteção", a autora vai mais longe ao argumentar que, na lei (ECA), "a proteção integral torna-se uma formação discursiva, uma referência regulatória, e produz estratégias de governo" (Scheinvar, 2015, p. 111), de modo que em nome da proteção vai se exigir a produção de conhecimentos, mas não mais somente sobre a criança, como era na perspectiva menorista, e sim sobre a família, mas a família pobre, da comunidade pobre.

Desse modo, quando uma situação de suspeita de abuso sexual é denunciada, uma série de procedimentos e/ou encaminhamentos são disparados em nome da proteção: "daí a Escola chamou o Conselho Tutelar"... "O conselheiro mandou a gente pra cá (SERVIÇO/espaço de escuta e reparação) e pra Delegacia pra registrar"; "a gente teve lá na Bento também” (endereço do IGP); "o Delegado mandou ela pra perícia"; "teve uma audiência na Promotoria, aí tinha os psicólogos..."; narrativas que tentam explicar seus percursos e, compreender os porquês de tanta "correria", mas que, fundamentalmente, revelam a emergência de interlocutores diversos, colocados em espaços múltiplos de garantia de direitos e, nesse sentido, está criado todo um aparelho para que a proteção seja garantida, está colocada em ação uma série de operadores do saber, poder e governo para que a vida de crianças e adolescentes das famílias pobres ${ }^{8}$ seja regulada.

Torna-se necessário, a partir daí,

Esquadrinhar a vida privada das famílias, investigar os vícios, os excessos, mas também as possibilidades hipotéticas, as potencialidades silenciosas e ocultas, os fluxos emocionais que perpassam a relação dos pais com a criança e da criança com a sociedade. Tudo isso deve ser averiguado e investigado detalhadamente, buscando identificar tendências e características. (Silveira, 2015 p. 71) 
Vivemos tempos em que a vida se articula em torno da lei, do direito e da política de produção de verdade (Scheinvar \& Lemos, 2012), eis o que sustenta o sistema de garantia de direitos de crianças e adolescentes. A lei, nesse caso o ECA, dá o tom, dá a segurança jurídica necessária para justificar todos os demais aparatos acionados em nome dos direitos de crianças e adolescentes.

A lei propõe regularidades, ao mesmo tempo em que se abre ao desvio, ao erro, ao ilícito e é, em geral, "nesse território que se faz a encomenda do atendimento psicológico" (Coimbra, Ayres, \& Nascimento, 2009, p. 34). Insere-se, nesse contexto da lei, uma intervenção em busca da verdade sobre os fatos denunciados e, assim, o que era apenas para ser um caso de polícia converte a notificação de abuso sexual em uma forma de governo da vida das pessoas, uma ordem baseada fundamentalmente nas ideias de gestão dos riscos, de modo que as questões relativas à vida e ao direito já não se separam mais (Nascimento, 2015).

E os riscos estão em toda a parte: na mancha de sangue na calcinha, no ânus machucado de um garoto, nas brincadeiras sexuais dos meninos se experimentando e se conhecendo, no comportamento "hipersexualizado" da criança, no alcoolismo e na drogadição do pai, entre outros tantos, mas, de fato, o cotidiano das práticas vai apontando para discursos que, ao instituírem determinadas verdades, são acionados no sentido de evitar a irrupção do risco, qual seja, o de que crianças ou adolescentes tenham sofrido ou possam vir a sofrer abuso sexual e, uma vez detectados os riscos, como aponta Robert Castel (1978), é preciso gerenciá-los. Entretanto, quando Castel faz este alerta, ele está nos advertindo do risco de apagarmos os processos de vulnerabilidade social, reduzindo a resolução dos problemas ao que ele chama de um governo pela psicologia, ou seja, a transformação do social no individual.

Se uma criança foi sexualmente abusada devemos intervir enquanto especialistas que somos não apenas no sentido de reparar prejuízos decorrentes da vitimização, mas atuar no sentido de prevenir que essa criança cresça e se converta num agressor sexual.

Os saberes constituídos acabaram por legitimar discursos que apoiam a ideia de que quem sofreu abuso sexual abusará sexualmente também. Tal assertiva não apenas institui o pânico acerca das possibilidades e riscos de vitimização, como instala uma proteção que é também controle; uma terapêutica que ao mesmo administra e que é também um dispositivo político (Castel, 1978).

Essa lógica da proteção que entrelaça disciplina e regulação não parece alcançar as demandas das/os usuárias/os quando denunciam uma situação de abuso sexual, pois se a lei faz a separação entre o permitido e proibido, busca a condenação, aparta o bem do mal, pune; como compreender que a vítima seja colocada em confissão, que à vítima e à sua família seja dito o que deve ser feito ou não? E, assim, entre a lei e a norma, enquanto especialistas psi, somos demandados a agenciar a produção de condutas esperadas e na tarefa de colaborar com a gestão dos riscos revelam-se os efeitos desse dispositivo psi que protege e ao mesmo tempo gerencia.

Assim, do/a Conselheiro/a Tutelar passando pelo/a Delegado/a, pelos/as peritos/ as e especialistas, chegando ao/a promotor/a e depois ao/a Juiz/a, fora tantos/as outros/ as interlocutores, todos/as estão habilitados/as, ou melhor, autorizados/as a proteger crianças e adolescentes em situação de violência e "quem protege pode definir condutas, crenças, desejos, de maneira a vigiar, examinar compreender, controlar e disciplinar" (Nascimento, 2015, p. 283). 
Diante de gestões múltiplas da vida, as famílias equilibram-se entre a aplicação de medidas judiciais e a profusão de saberes que percorrem a rede de atendimento em todas as direções, produzindo, assim, relações de poder em todos os níveis de atendimento e, nesse cenário de "ação assistencial e tutelar os usuários em geral, chegam sentindo-se ameaçadas pelo poder da justiça, pelo saber do técnico, com demandas quando não abafadas e tímidas, impregnadas de desqualificação" (Coimbra, Ayres, \& Nascimento, 2009, pp. 34-35).

Vivemos tempos de expansão dos ideais e princípios judiciais para as mais diversas esferas da vida, fenômeno que passou a se chamar de judicialização, que se estende desde a regulação de questões do cotidiano até as esferas eminentemente punitivas.

Nas palavras de Foucault (2012), as formas jurídicas "nasceram em ligação direta com a formação de certo número de controles políticos e socais no momento da formação da sociedade capitalista, no final do século XIX” (p. 12), ou seja, quando o controle penal, para poder operar, precisou de poderes paralelos à justiça, tais como a polícia, para vigiar, e as instituições psicológicas, psiquiátricas, médicas, pedagógicas e criminológicas para corrigir.

Nesse sentido, o encontro entre o judicial e psicológico não configura um achado recente, trata-se de uma configuração que vem se construindo e se rearranjando ao longo dos últimos dois séculos. E a Doutrina da Proteção Integral, implementada a partir do ECA, prestou-se ainda mais a essa aproximação e tem provocado reflexões sobre o modo de exercício de poder nas confluências das práticas psi e jurídicas contemporâneas.

\section{Conclusão}

Movidos pela lógica do dispositivo da sexualidade vimos crescer a instrumentalidade conferida ao abuso sexual, o qual se converteu numa questão que produz estranhamentos e inquietações capazes de acionar o sistema de proteção e promoção de direitos. O abuso sexual torna-se prescritivo e determinante para a proteção de crianças e adolescentes, porta de entrada no labirinto das garantias de direitos e um modo de regulação da sexualidade que se infiltra no interior das famílias.

Assim, o abuso sexual, enquanto uma construção social da violência, não somente passa a ocupar um lugar determinante e central em nome da proteção, como define os conteúdos pertinentes, qualifica os interlocutores e os relatos considerados verdadeiros e legitima a emergência da noção da vítima, sobre quem se desenham as políticas de cuidado para reparar o sofrimento imposto pela violência.

Tomados pela lógica do trauma que associa violência à dor e sofrimento, movidos pela incitação a falar sobre sexo e a expressão obrigatória dos sentimentos, nos movemos na direção, sob a justificativa de garantir direitos, da proliferação dos espaços de escuta, de reparação, espaços em sua maioria constituídos por saberes psi; ao mesmo tempo em que nos inserimos numa época em que prevalece "o ideal de que tudo deve ser legislado", um tempo em que "exige-se da democracia e do seu arsenal jurídico, colocar as mãos sobre tudo o que concerne à vida dos cidadãos" (Santiago, 2008, p. 58). 
Enfrentar as denúncias de abuso sexual tem significado a aplicação de medidas pro-tetivas previstas na lei, convertendo as disposições legais no eixo das práticas, ou seja, amparado por lei, e em nome da proteção, Conselheiros/as Tutelares, Delegados/ as, Promotores/as e Juízes/as requisitam atendimento e/ou avaliação psicológica para diagnosticar e reparar a situação; requisitam exames periciais para construir provas e, nesse cenário, inserem os saberes das/os especialistas. São os diagnósticos dos/as experts que encaminharão os lugares que as vítimas e suas famílias ocuparão no circuito da proteção.

Quando o abuso sexual é denunciado, se apagam a falta de dinheiro para sobreviver, as necessidades de saúde, a inexistência de moradia, a busca de vaga na escola, entre tantas outras mazelas vividas cotidianamente pelos/as pobres que atendemos. Essa perspectiva de um Estado que deveria defender os direitos, mas onde cabe ao/à cidadão/ã fazer por merecer, um Estado que, movido pela perspectiva jurídica, individualiza e privatiza as relações, convocará o especialismo psi para produzir as verdades sobre essas vidas. Assim, o discurso psicologizante referente ao sujeito passa a ser a medida de todas as coisas e, mais uma vez, só que agora pelo caminho da psicologização, individualizamos e privatizamos a experiência do abuso sexual.

O investimento no domínio privado dessa psicologia judicializada for nece a legitimidade científica à tecnologia do ajustamento. É necessário, contudo, que compreendamos que ao atender/acolher uma criança ou adolescente que tenha sofrido abuso sexual não podemos reduzi-la/o exclusivamente ao diagnóstico de abuso, sem considerar todos os atravessamentos que foram construindo o cenário da vitimização sexual. 


\section{Notas}

1 Trata-se da Síndrome de Alienação Parental (SAP) - É a manipulação do/a genitor/a guardião/ã para afastar os/as filhos/as do/a genitor/a não guardião/ã. Pais e mães que mentem, caluniam e tramam, no sentido de programar a criança para que, depois da separação, odeie um dos pais com o objetivo de afastar o/a filho/a do/a ex-parceiro/a. Em casos extremos, mas não tão raros, a criança é estimulada pelo/a guardião/ã a acreditar que apanhou ou sofreu abuso sexual.

2 Embora tenhamos presente as críticas feitas ao uso do termo adolescentes porquanto pode sugerir e/ou reforçar as compreensões desenvolvimentistas que atravessam o discurso biomédico e psicológico, ainda assim fez-se a opção pelo seu uso, por ser a nomenclatura difundida no âmbito do Sistema de Garantia de Direitos das pessoas menores de 18 e maiores de 12 anos de idade.

3 NACA - Núcleo de A tenção à Criança e ao Adolescente, trata-se de uma Organização da Sociedade Civil de Interesse Público (OSCIP), localizada no município de Pelotas/RS, que atua na avaliação, diagnóstico e tratamento de crianças, adolescentes e suas famílias em situação de maus tratos, abuso sexual e negligência, numa abordagem interdisciplinar, contando com profissionais da psicologia, serviço social, pedagogia e direito, acolhendo encaminhamentos feitos pelo Conselho Tutelar, Delegacias da Mulher e da Criança e do Adolescente, Justiça e Ministério Público.

4. A análise do trabalho realizado no NACA há duas décadas tem evidenciado que, embora possa haver entre os seus usuários pessoas de todas as classes e condições socioculturais, a maior parte é composta, ainda, por pessoas sem renda ou aquelas cuja renda familiar não excede dois salários mínimos mensais.

5 Não buscamos, de forma alguma, como ressaltamos em diversas partes do texto, desqualificar o abuso como uma violação grave e com consequências psíquicas severas. $\mathrm{O}$ que intentamos é mostrar que seu uso como fonte única de legitimação de demandas se torna um apagador de outras demandas e termina por restringir outras formas legítimas de acesso às políticas de proteção. Fazer esse alerta em um momento político conservador e reacionário, onde os e as atuais mandatários/as buscam culpabilizar as vítimas, pode levar a leituras mal intencionadas. Entretanto, acreditamos fortemente que a crítica é o que move o pensamento e ceder ao conservadorismo, evitando complexificar análises, é ceder ao autoritarismo.

6 Os nomes da adolescente e da sua avó foram alterados, respeitando-se o previsto no Termo de Consentimento Livre e Esclarecido - TCLE, que trata da confidencialidade, e ainda porque todos os procedimentos envolvendo crianças e adolescentes em medida protetiva devem preservar o anonimato. 
7 A história de Rodrigo, outra criança atendida, deixa evidente que muito antes de uma possível vitimização sexual ele já estivera exposto a inúmeras violações: o pai fora assassinado por traficantes; a mãe tem déficit intelectual importante e ainda revela um quadro psiquiátrico não elucidado (por quem participou dos atendimentos); a família não tem renda, não tem benefício social e por inúmeras vezes Rodrigo andou pelas ruas mendigando e outras vezes furtando e, até então, nem a Escola, nem a UBS e o/ou CRAS do território onde vivia Rodrigo e sua mãe acionaram a rede de proteção; aliás, não fossem as violações decorrentes da desproteção social dessa criança, ele não teria chegado ao limite de estar se prostituindo aos 10 anos de idade para se sustentar. Foi a notícia de uma possível prostituição que fez com que Rodrigo fosse retirado da mãe, colocado sob a guarda de uma tia e encaminhado para múltiplos serviços.

8 Mesmo que já há algum tempo tem se evitado vincular a ideia de violência com pobreza, não apenas por sua insuficiência explicativa, mas por seu potencial estigmatizante, não há, contudo, como negar que o modo como ricos e pobres lidam com situações de violência difere substancialmente. Se entre os ricos a violência contra as crianças e adolescentes é ocultada para proteger a família, o agressor, o status, o patrimônio ou a própria criança de possíveis estigmas, por outro lado, aos pobres restam os serviços públicos para reparar os danos da violência, e, deste modo, as ocorrências de violência tornam-se mais visíveis entre os pobres (Scobernatti, 2012). 


\section{Referências}

Barros, R. B. (2013). Grupo: a afirmação de um simulacro. Porto Alegre: Sulina; Editora UFRGS.

Brito, L. M. T. (1993). Separando. Rio de Janeiro: Relume Dumará.

Castel, R. (1978). A Ordem Psiquiátrica: a idade de ouro do alienismo. Rio de Janeiro: Graal.

Coimbra, C. M. B, Ayres, L. S. M., \& Nascimento, M. L. (Orgs.). (2009). Pivetes, Encontros entre a Psicologia e o Judiciário. Curitiba: Juruá.

Fassin, D. \& Rechtman, R. (2007). Lémire du traumatisme: enquête sur la condition de Victim. Paris: Flammarion.

Fischer, M. R. B. (2003). Foucault revoluciona a Pesquisa em Educação? Perspectiva, Florianópolis, 21(2), 371-389.

Foucault, M. (1998) Microfísica do Poder (R. Machado, trad., 13a ed.). Rio de Janeiro: Graal. Foucault, M. (2007). A História da Sexualidade II: o uso dos prazeres (12 ${ }^{\mathrm{a}}$ ed.). Rio de Janeiro: Graal.

Foucault, M. (2012). A Verdade e as Formas Jurídicas. Rio de Janeiro: NAU.

Nascimento, M. L. (2015). Proteção à infância e a adolescência nas tramas da biopolítica. In H. Resende (Org.), Michel Foucault: o governo da infância (pp. 281-290). Belo Horizonte: Autêntica.

Santiago, J. (2008). Foucault e o neo-higienismo contemporâneo In I. F. Passos (Org.), Poder, normalização e violência: incursões foucaultianas para a atualidade (pp. 53-62). Belo Horizonte: Autêntica.

Sarti, C. (2011). A vítima como figura contemporânea. Dossiê Caderno CRH, Salvador, 24(61), $51-61$.

Scheinvar, E. (2015). A aplicação do ECA tem se desviado da sua proposta original: Estado de Direito e formação discursiva no campo da criança e do adolescente. In H. Resende (Org.), Michel Foucault: o governo da infância (pp. 103-113). Belo Horizonte: Autêntica.

Scheinvar, E. \& Lemos, F. C. S. (2012). Os direitos da criança e do adolescente: o caminho da judicialização, Universidade e Sociedade, 50, 72-81. Recuperado de https://issuu.com/andessn/ $\underline{\mathrm{docs}} / 50$

Scobernatti, G. (2012). Entre amores invisíveis e silenciados: histórias de abusadoras sexuais. Pelotas/RS: EDUCAT.

Silveira, D. S. S. (2015). Governamentalidades, saberes e políticas públicas na área e Direitos Humanos da Criança e do adolescente. In H. Resende (Org.), Michel Foucault: o governo da infância (pp. 57-83). Belo Horizonte: Autêntica.

Spink, M. J. (2013). Práticas discursivas e produção de sentidos no cotidiano: aproximações teóricas e metodológicas. Rio de Janeiro: Centro Edelstein de Pesquisas Sociais. 


\section{GISELE SCOBERNATTI \\ https://orcid.org/OOOO-0002-4551-4828}

Universidade Federal do Rio Grande do Sul, Programa de Psicologia Social Doutora em Psicologia Social e Institucional.

Endereço: Rua Padre Anchieta, 4036, Pelotas, RS, CEP 96015-420.

E-mail: giselescobernattio184@gmail.com

\section{HENRIQUE CAETANO NARDI}

https://orcid.org/0000-0001-6058-1642

Professor, Universidade Federal do Rio Grande do Sul, Doutor em Sociologia.

E-mail: hcnardi@gmail.com

\begin{tabular}{|c|c|}
\hline Histórico & $\begin{array}{l}\text { Submissão: 12/09/2019 } \\
\text { Revisão: 14/04/2020 } \\
\text { Aceite: 28/05/2020 }\end{array}$ \\
\hline Contribuição dos autores & $\begin{array}{l}\text { Concepção: G.S.; H.N. } \\
\text { Coleta de dados: G.S. } \\
\text { Análise de dados: G.S.; H.N. } \\
\text { Elaboração do manuscrito: G.S.; H.N. } \\
\text { Revisões críticas de conteúdo intelectual } \\
\text { importante: H.N. } \\
\text { Aprovação final do manuscrito: H.N. }\end{array}$ \\
\hline Consentimento de uso de imagem & Não se aplica \\
\hline Aprovação, ética e consentimento & Não se aplica \\
\hline Financiamento & Não houve Financiamento \\
\hline
\end{tabular}

